\title{
SENTIDO E REALIDADE EM MITOS INDÍGENAS: UM EXAME SEMIÓTICO DE NARRATIVAS DE CONQUISTA DO FOGO
}

CLEBSON LUIZ DE BRITO ${ }^{1}$

$U F M G$

\begin{abstract}
RESUMO: Este artigo apresenta uma análise, à luz da semiótica francesa, de dois mitos de sociedades indígenas brasileiras que tratam da aquisição do fogo. O objetivo é demonstrar que os textos examinados constituem um todo de sentido coerente e que disso fazem parte elementos, não raro, tomados como indício de caos discursivo, como a presença de animais dotados do traço semântico /humano/. A análise revela que a conquista do fogo, nos dois textos, configura uma figurativização de um processo de normalização da realidade que explica a elevação do homem/índio pela cultura em relação aos seres circunscritos ao domínio da natureza.
\end{abstract}

PALAVRAS-CHAVE: Mito indígena; Aquisição do fogo; Semiótica francesa; Realidade.

ABSTRACT: This article presents an analysis, under the light of French semiotics, of two myths of Brazilian Indian tribes that take care of the acquisition of the fire. The aim is to demonstrate that the texts examined are coherent as a whole and that certain elements, often taken as evidence of discursive chaos, such as the presence of animals with the semantic trace /human/, are also part of that. The analysis reveals that in both texts the conquest of the fire sets a figurativization of a process of normalization of the reality that explains the cultural elevation of the man/Indian in relation to beings confined to the sphere of the nature.

KEYWORDS: Indian myths; Acquisition of the fire; French semiotics; Reality.

\section{Introdução}

\section{O discurso mítico das sociedades indígenas detém, contemporaneamente, um estatuto ambíguo, como bem observou Eliade (2007), sendo tomado tanto como algo dotado de sentido e de valor}

\footnotetext{
${ }^{1}$ Possui graduação em Letras pela UFMG (2007) e mestrado em Linguística do Texto e do Discurso também pela UFMG (2011). Desde 2012 é doutorando do Programa de Pós-Graduação em Estudos Linguísticos da Faculdade de Letras da UFMG com bolsa da Fapemig. E-mail: clebsonlb@gmail.com.
}

Espaço Ameríndio, Porto Alegre, v. 7, n. 1, p. 196-213, jan./jun. 2013. 
CLEBSON LUIZ DE BRITO - Sentido e realidade em mitos indígenas...

positivo, quanto como mera fabulação, sinônimo de atraso, fruto de mentes ingênuas ou coisa semelhante. A primeira concepção é defendida há praticamente um século por importantes estudiosos, ao passo que a segunda, rechaçada por estes, prevalece ao menos no senso comum como resquício de uma visão reducionista de mito muito comum durante o predomínio da Filosofia da llustração e do Positivismo, nos séculos XVIII e XIX.

O mito ameríndio, nosso objeto de análise aqui, também não escapa a esse estatuto ambíguo. Muitas narrativas míticas ameríndias, para ficarmos em apenas um exemplo de trato do mito a partir da primeira das concepções acima, integram o corpus do respeitado trabalho desenvolvido por Lévi-Strauss nos volumes de Mitológicas. Tomando as narrativas indígenas como objeto de estudo e submetendoas ao método estrutural, Lévi-Strauss (1991) demonstrou que elas são individualmente dotadas de sentido e estruturalmente organizadas. Mais que isso: defendeu que mitos aparentemente caóticos têm sua configuração mais superficial motivada por processos de transformação lógicos pelos quais passam. A reconstituição desses processos pelo antropólogo estruturalista revelou origens e elementos comuns para mitos à primeira vista bem diferentes uns dos outros, o que ficou conhecido pela expressão "harmonias insuspeitas".

Apesar de posições e estudos como os de Lévi-Strauss, o mito indígena parece ainda, em nossa sociedade, fadado a uma abordagem/leitura centrada em imagens capazes de encantar pela "ingenuidade", "simplicidade", em vez de centrada no(s) sentido(s) que o texto suscita. Essa forma de tomar o mito indígena acaba por reduzi-lo à sua dimensão figurativa, reproduzindo, de certo modo, a visão de mito combatida pelos estudiosos: a de que se trata de algo caótico, fabulador.

É em função desse estatuto ambíguo do mito como um todo e do mito ameríndio em especial que realizamos o presente trabalho. Apresentamos a seguir uma análise, à luz da semiótica francesa (doravante: semiótica), de dois mitos de sociedades indígenas brasileiras que contemplam a conquista do fogo, tema comum a diversas mitologias. Nosso objetivo é demonstrar, na esteira da primeira das concepções de mito apontadas nesta introdução, que os textos 
examinados constituem um todo de sentido coerente, do qual fazem parte elementos, não raramente, tomados como indício de caos discursivo.

Antes de fazer isso, no entanto, vamos descrever em linhas gerais a teoria utilizada como suporte para a análise, o que faremos na seção subsequente.

\section{A semiótica francesa e seus elementos de análise}

A semiótica tem por propósito desvelar não apenas o sentido, aquilo que um dado texto diz, mas, sobretudo, as estruturas significantes por meio das quais esse sentido se constitui, isto é, como o texto faz para dizer o que diz. Tendo em vista esse objetivo, a semiótica, numa perspectiva gerativa do sentido, postula a existência de três diferentes patamares de significação, os quais constituem um percurso que vai do mais simples e abstrato ao mais complexo e concreto. Esses patamares dizem respeito ao plano de conteúdo (dos significados), que, apenas ao se juntar a um plano de expressão (seja ele verbal, não verbal ou sincrético), resulta na produção textual efetiva, com a qual se defronta o leitor.

Esse postulado desemboca, por sua vez, na proposta de um simulacro teórico-metodológico para abordagem do plano de conteúdo do texto: o percurso gerativo de sentido. Trata-se, com efeito, de um dispositivo que permite a reconstituição da geração do sentido, engendrado na articulação dos três níveis (ou patamares) postulados na teoria. Cada um dos níveis do percurso gerativo apresenta um componente sintáxico ${ }^{2}$, relativo aos arranjos dos conteúdos, e um componente semântico, relativo aos conteúdos investidos nos arranjos sintáxicos. Vamos nos deter nas próximas linhas justamente na descrição dos diferentes níveis do percurso gerativo e dos seus respectivos componentes.

O patamar inicial (mais simples e abstrato) do processo de geração do sentido é o nível fundamental. Nesse patamar a significação

\footnotetext{
${ }^{2} \mathrm{O}$ termo sintático também é usado em semiótica, mas optamos por sintáxico, a exemplo de Tatit (2002), para evitar confusão com a acepção do termo no campo da gramática normativa.
} 
CLEBSON LUIZ DE BRITO - Sentido e realidade em mitos indígenas...

é apreendida, do ponto de vista semântico, sob a forma de uma oposição do tipo /a/ versus/b/, por exemplo: /natureza/ versus /cultura/ ou /liberdade/ versus /opressão/. Além disso, esses termos se inserem em um sistema axiológico, em que um se mostra positivo, atraente (eufórico) e o outro, negativo, repulsivo (disfórico) (GREIMAS e COURTÉS, 2008).

Já do ponto de vista sintáxico, o nível fundamental compreende as operações lógicas e abstratas de asserção e negação (FIORIN, 2006). Trata-se de operações que permitem, dada uma determinada categoria semântica de base, uma transição de um termo a outro e, com isso, um percurso fundamental que dê conta do que se mostra na sucessividade do texto. Um relato sobre reflorestamento, por exemplo, implica as seguintes operações elementares: uma afirmação inicial do termo /civilização/, quando prevalecia a degradação do ambiente, seguida de uma negação desse termo - a / não civilização/ - e uma afirmação final do termo / natureza/ (pelo reflorestamento das áreas).

O nível narrativo, por sua vez, é o patamar que atualiza os valores virtuais do nível fundamental e os insere numa organização narrativa que simula o fazer do homem no mundo. Nesse nível, o sentido é apreendido como configurações narrativas, marcadas pelas transformações de estado que subjazem aos discursos e por tudo o que gira em torno de tais transformações: as relações contratuais que levam os sujeitos a agir, as qualificações que permitem a ação, a busca por objetos de valor etc.

O componente semântico do nível narrativo abrange as modalizações, entre as quais se acham as que dizem respeito às qualificações do sujeito para a ação, isto é, as modalizações pelo fazer. Para agir, o sujeito tem de ser dotado de um /querer/ ou um /dever fazer/ e ainda de um /saber/ e de um /poder fazer/. Há, nesse componente, também, as modalizações que incidem sobre a relação entre sujeito e objeto, gerando efeitos de sentido passionais. $\mathrm{O}$ /querer ser/ modaliza uma relação desejável; o /poder ser/, uma relação possível, e assim por diante.

Em um relato sobre reflorestamento, retomando o exemplo dado anteriormente, a relação entre homem e área verde é tida como desejável, modalizada pelo /querer ser/, e ainda como possível, 
CLEBSON LUIZ DE BRITO - Sentido e realidade em mitos indígenas...

modalizada pelo / poder ser/, uma vez que a degradação da vegetação é combatida. A combinação dessas modalizações resulta, por sua vez, em efeitos passionais de satisfação para o sujeito. Além disso, para haver reflorestamento, é preciso, por exemplo, dispor de mudas de árvores, conhecer possíveis técnicas de plantio e de regeneração do solo. Tudo isso, além de pressupor um /querer fazer/, concretiza, nesse hipotético relato, um /poder/ e um /saber fazer/, sem os quais não se realiza a ação de reflorestar a área degradada.

A sintaxe narrativa, por seu turno, é o âmbito da organização e descrição das transformações de estado propriamente ditas. Nela partimos da noção de enunciado elementar, que se apresenta de duas formas possíveis: o enunciado de estado - que manifesta relações de junção (conjunção e disjunção) entre os actantes (sujeito e objeto) - e o enunciado de fazer - que incide sobre o enunciado de estado, levando da disjunção à conjunção (ou vice-versa), processo tomado como uma narrativa mínima (LARA, 2004) ou programa narrativo (PN).

Nas narrativas os PNs tendem a se organizar em um esquema narrativo canônico, um encadeamento lógico de quatro PNs específicos que dão a uma sequência narrativa o aspecto de um todo organizado e finito (BERTRAND, 2003). Os PNs que formam o esquema narrativo canônico são 1) a manipulação - fase em que se estabelece um contrato entre um destinador-manipulador e um destinatário-sujeito, de modo que o último deva ou queira realizar uma dada transformação; 2) a competência - fase em que o sujeito, já manipulado, adquire um /poder/ e um /saber fazer/ (as modalizações de que falamos acima); 3) a performance - fase da transformação principal da narrativa; e 4) a sanção - fase em que a atuação do sujeito de fazer (aquele responsável pela performance) é avaliada/reconhecida (sanção cognitiva) por um destinador-julgador, podendo resultar numa retribuição: prêmio ou castigo (sanção pragmática), segundo a performance seja avaliada positiva ou negativamente.

Cabe lembrar, ainda, que a organização narrativa é marcada por uma estrutura polêmica. Como explica Barros, "os objetos-valor circulam em um espaço fechado e a aquisição de um objeto por um sujeito corresponde à sua privação para outro sujeito" (BARROS, 1988, p. 43). Nesse sentido, há sempre um desdobramento da narrativa em 
duas perspectivas antagônicas que envolvem destinador e antidestinador, os quais representam sistemas de valores contrários ou contraditórios, além de sujeito e antissujeito, rivais que se caracterizam pelo interesse no mesmo objeto de valor (BARROS, 1988).

Chegamos agora ao nível discursivo, patamar que compreende a conversão das estruturas semióticas mais abstratas, tais como foram apresentadas acima, em discurso-enunciado. Na sintaxe discursiva, examina-se a ancoragem do discurso-enunciado nas categorias de pessoa (eu/ele), tempo (agora/então) e espaço (aqui/lá) (LARA, 2004), o que produz, em suma, efeitos de sentido de subjetividade ou objetividade. Além disso, são examinados procedimentos diversos que o enunciador utiliza para persuadir (fazer crer) o enunciatário a aceitar o discurso produzido.

Na semântica discursiva, por sua vez, "examinam-se os temas, as figuras e as isotopias, elementos que concretizam as estruturas do nível anterior (o narrativo)" (LARA e MATTE, 2009, p. 69). Temas são investimentos semânticos que não remetem ao mundo natural, mas auxiliam, em razão de sua natureza puramente conceitual, na interpretação da realidade (FIORIN, 2006). As figuras discursivas, por sua vez, são "determinadas por traços 'sensoriais', que concretizam e particularizam os discursos abstratos" e criam efeitos de realidade (BARROS, 1988, p. 117). Já isotopia, termo emprestado da Física, designa, em semiótica, a reiteração, recorrência de traços semânticos que garantem a coerência de um texto (BARROS, 1988).

Há, assim, no nível discursivo, duas possibilidades de concretização do sentido: a tematização e a figurativização. Elas se ligam, por sua vez, a dois diferentes tipos de textos que refletem duas formas de abordar a realidade: os temáticos, que procuram explicá-la, justificá-la; e os figurativos, tipo a que pertence nosso objeto de estudo (as narrativas míticas), que criam um simulacro do mundo e permite uma racionalização indutiva.

Cabe dizer, porém, que não há textos apenas figurativos, pois as figuras necessariamente remetem a temas; todos os discursos contêm uma tematização de estruturas narrativas, quer haja o posterior processo de figurativização ou não. É importante que se frise isso, inclusive, porque a compreensão dos textos predominantemente 
CLEBSON LUIZ DE BRITO - Sentido e realidade em mitos indígenas...

figurativos depende da apreensão dos temas que subjazem à figurativização (BERTRAND, 2003), como veremos a seguir.

\section{Análise dos textos}

As duas narrativas de conquista do fogo contempladas no presente artigo foram colhidas da mitologia dos índios Craô (texto 1) e dos Parintintin (texto 2), grupos indígenas do Brasil. Antes de iniciarmos a análise propriamente dita, gostaríamos de apresentar de forma breve os povos mencionados e de reproduzir os textos que serão examinados à luz da teoria semiótica.

Os Craô vivem atualmente numa reserva localizada nos municípios de Itacajá e Goiatins, no Tocantins. Segundo Melatti (1972), esse grupo, que fala uma língua pertencente à família Jê, forma, com vários outros grupos, os Timbira, que representam uma unidade do ponto de vista linguístico e cultural. O texto colhido da mitologia desse grupo é o que apresentamos abaixo.

\section{A versão craô de aquisição do fogo (Texto 1)}

Os índios antigos não tinham fogo; comiam carne crua seca ao sol. Um deles viu um ninho de arara num buraco de uma encosta e levou o irmão da esposa, que era novinho, para apanhar os filhotes. Cortou um pau comprido e fez escada para o menino subir. Este, entretanto, ficou com medo da arara, que estava brava. O marido da irmã recomendou-lhe que fizesse um ganchinho com um ramo para puxá-la pelo pescoço. Mas a arara quebrou o ganchinho. Apesar da insistência do cunhado, o menino não conseguia puxar a arara e jogá-la pra baixo. Por isso, aquele se zangou, fez cair a escada e deixou o irmão da esposa lá em cima. Foi embora, nada contou em casa e nem a mulher perguntou pelo irmão.

O menino ficou passando fome e sede. Aos poucos a arara que trazia alimento para os filhotes se acostumou com ele, e o menino comia o buriti que ela trazia. E assim aguentou por dois meses.

Então, um jaguar que estava caçando chegou ao pé da encosta. O jaguar, vendo sua sombra projetada no chão, tentou por duas vezes pegá-la, até que se deu conta que era do menino que estava no alto. Tendo lhe 
CLEBSON LUIZ DE BRITO - Sentido e realidade em mitos indígenas...

perguntado por que lá estava, o jaguar ouviu-lhe a história e depois ofereceu-se para apará-lo, se ele de lá pulasse. $O$ menino se recusou, alegando que o jaguar o comeria. O jaguar então pediu-lhe que jogasse os filhotes de arara. O menino jogou um e depois outro, e o jaguar os comeu. Então insistiu que o menino pulasse e assegurou que não o comeria, pois já tinha comido as araras. O menino fechou os olhos e pulou.

O menino estava com fome, sede e todo sujo de excrementos de arara. O jaguar o levou a um brejo, onde ele bebeu e se lavou. Depois o jaguar o levou para casa, onde o apresentou à esposa, que queria comer logo o menino. O marido, porém, disse que iriam criá-lo.

Depois de uns dias, o jaguar saiu para caçar e deixou o menino com a mulher. A onça o ameaçou com as garras e os dentes e o menino fugiu em busca do jaguar, que teve de voltar da caçada sem nada e recomendar à esposa que não fizesse mais assim. E saiu de novo. Porém, por mais duas vezes teve de voltar porque sua mulher de novo assustava o menino e ele corria em busca de seu socorro. Só conseguiu trazer uma tatupeba, que mal serviu para a refeição.

No dia seguinte o jaguar foi caçar de novo, e mais uma vez teve sua atividade interrompida pela fuga do menino ameaçado pela onça. O marido então endireitou flechas no fogo, fez um arco para o menino e recomendou-Ihe que, se fosse ameaçado, flechasse a onça bem na mão e corresse para sua aldeia, que era logo depois do morro e do riacho; a onça não o perseguiria porque estava grávida. Uma vez ausente o jaguar, a onça ameaçou novamente o menino, que a flechou em ambas as mãos e correu para sua aldeia.

$\mathrm{Na}$ aldeia, o menino contou ao pai que a onça tinha o fogo. Os moradores foram então à casa da onça e roubaram-Ihe o fogo, que ficou gritando que pelo menos deixassem uma brasinha para ela (MELATTI, 2008, n./p.).

Os Parintintin, segundo grupo mencionado, tinham, de acordo com Kracke (2005), um território que se estendia da região leste do rio Madeira até a boca do rio Machado, a leste do rio Maici. Hoje a maioria de sua reduzida população, falante original de uma língua da família Tupi-Guarani, vive em duas Terras Indígenas no município de Humaitá, no Amazonas. Segue abaixo o texto da mitologia parintintin que selecionamos. 


\section{O roubo do fogo, dos índios Parintintin (Texto 2)}

Antigamente Kawahiwa [autodenominação dos Parintintin ${ }^{3}$ ] secava a comida ao sol. Não havia fogo. O chefe dos Kawahiwas, Bahira, foi ao mato, fazer uma experiência.

Cobriu-se de cupim e deitou-se, fingindo que estava morto. Veio a mosca varejeira, viu aquele morto e foi avisar o Urubu. O Urubu era dono do fogo, e o trazia sempre consigo, debaixo das asas, dizem. O Urubu desceu do céu, então, acompanhado de outros urubus, da mulher e dos filhos. O Urubu era gente: tinha mãos. Preparou o moquém e pôs debaixo dele o fogo, mandando que os filhos vigiassem. Os filhos viram que o morto estava bulindo. Disseram ao Urubu. O Urubu não acreditou nos filhos; disse-Ihes que fossem matando as varejeiras com as flechinhas que haviam trazido. Quando o fogo, debaixo do moquém, estava bem aceso, Bahira se levantou, de repente, e o roubou, fugindo. O Urubu saiu a persegui-lo, com a sua gente. Bahira escondeu-se no oco de um pau. O Urubu e sua gente entraram no oco do pau, atrás de Bahira. Bahira saiu do outro lado e atravessou um tabocal cerrado. O Urubu não o pôde acompanhar. Bahira chegou à margem do rio largo, largo. A gente dele, os Kawahiwas, estava na margem de lá. E era muita gente, muita. Bahira pensou como lhe levaria o fogo roubado ao urubu.

Chamou a cobra-surradeira. Pôs-lhe o fogo na costa e mandou-a levá-lo para a sua gente. Como a surradeira corre muito, logo saiu a toda. No meio do rio, porém, a cobra morreu queimada. Bahira, com um cambito [vara com ponta em forma de gancho], puxou o fogo para si. E o pôs noutras cobras. As cobras iam até o meio do rio, mas não resistiam ao calor do fogo: morriam. Bahira puxou o fogo, pegou o camarão e pôsIhe o fogo na costa. O camarão foi até o meio do rio, mas não resistiu ao calor do fogo, morrendo queimado, todo vermelho. Bahira puxou o fogo para si de novo. Pegou o caranguejo e pôs-lhe fogo à costa. O caranguejo foi até no meio do rio, mas morreu, ficando vermelho como o camarão, que se queimara. Bahira puxou o fogo e o pôs na costa da saracura, que anda muito, foi até o meio do rio, mas morreu queimada. Então Bahira pegou o Cururu. O sapo foi aos pulos até perto dos Kawahiwas, à espera noutra margem do rio. Como já ia meio morto, de cansado, os Kawahiwas o puxaram para a terra com um cambito e uma vara. E

\footnotetext{
${ }^{3}$ As explicações entre colchetes são do organizador.
} 
CLEBSON LUIZ DE BRITO - Sentido e realidade em mitos indígenas...

levaram o fogo para a maloca. Bahira, do outro lado, pensou como deveria atravessar o rio largo. Mas Bahira era um grande pajé; fez o rio estreitar-se, deu um pulo por sobre as águas e foi à procura de sua gente.

Desde aquele dia os Kawahiwas tiveram fogo e puderam assar peixes e caçar no moquém. E o Cururu virou pajé (SILVA, 1957, p. 174-175).

Apresentados os textos selecionados, cumpre dizer ainda que, para dar mais agilidade à análise, optamos por abordar as narrativas conjuntamente, tendo em vista seus muitos elementos convergentes. Além disso, como nosso objetivo não é esgotar os textos (nem poderíamos ter essa pretensão), vamos priorizar na análise o projeto textual/discursivo que estes apresentam, ressaltando o papel dos elementos que, a princípio, podem parecer sem propósito ou absurdos. Dito isso partamos ao exame dos textos, começando por uma síntese do que encontramos no nível narrativo.

Tanto o texto dos índios Craô (texto 1) quanto o dos Parintintin (texto 2) apresentam o fogo como um objeto de valor (Ov) descritivo ${ }^{4}$ e já existente 5 , estando inicialmente na posse não dos homens/índios, mas na dos animais (o casal onça e jaguar, no texto 1, e o urubu, no texto 2). Em dado momento nas narrativas, o sujeito homens/índios se apropria desse Ov, passando a usufruir de seus valores. Essa apropriação pelos homens/índios, em função da estrutura polêmica da narrativa, como explicamos anteriormente, tem como consequência a privação do antissujeito (os animais que detinham inicialmente o Ov), que se vê espoliado do fogo. Essa é, em suma, a organização básica observada nas estruturas narrativas dos textos em análise.

No nível discursivo, por sua vez, encontram-se investimentos semânticos, e mais especificamente figurativos, que podem, à primeira vista, causar estranheza. Tanto no texto 1 quanto no 2 o papel actancial de antissujeito, por exemplo, é figurativizado por certos animais - um jaguar e uma onça, no primeiro caso, e um urubu, no segundo. Não

\footnotetext{
${ }^{4}$ Greimas e Courtés (2008) definem valores descritivos como objetos passíveis de consumo, acúmulo e manuseio. São diferentes, portanto, dos valores modais, de que se servem os sujeitos para conseguir os valores descritivos.

5 O narrador do texto 2 afirma que "não havia fogo", mas devemos entender que este não existia apenas em poder dos índios, já que o urubu, segundo o próprio narrador, era o dono do objeto antes de sua conquista pelos homens.
} 
CLEBSON LUIZ DE BRITO - Sentido e realidade em mitos indígenas...

bastasse isso, esses animais estão, como explicaremos em mais detalhes a seguir, dotados de um traço semântico / humano/.

Os elementos apontados são recorrentes nos mitos indígenas e, não raro, são tomados no âmbito do senso comum como indício de discurso caótico e fabulação incoerente. Esses recursos discursivos, no entanto, são pertinentes com a narrativa de conquista do fogo e integram-se, de forma coerente, ao projeto textual/discursivo materializado nas narrativas. Isso é o que vamos explicar nas linhas seguintes, observando inicialmente outros elementos da semântica discursiva.

Observe-se que há, nos textos analisados, recorrências de traços semânticos de uma isotopia alimentar. Veja-se que, por exemplo, o narrador em ambas as narrativas explica de antemão (nos primeiros períodos dos textos) que os índios antigos comiam carne crua seca ao sol. Além dessa figura (comer carne crua seca no sol), há uma série de outras que se referem a uma isotopia alimentar.

No texto 1 , inicialmente o pequeno herói é abandonado num ninho de araras no alto da encosta pelo vingativo cunhado. Preso ali, tem sua sobrevivência precariamente assegurada graças ao instinto materno da arara, que traz buritis como alimento para o "novo filhote". A isotopia alimentar está, desse modo, presente nesse trecho inicial do texto por meio de uma figura (o buriti) que remete à alimentação vegetariana e não humana. Em seguida, para deixar o ninho da arara, o menino lança para o jaguar os filhotes da ave, que são imediatamente devorados pelo felino. Aqui a isotopia alimentar é acionada pela figura comer os filhotes da arara, que se refere à alimentação carnívora e animal (já que os filhotes da arara são devorados crus). Após aquilo que podemos considerar um estabelecimento de contrato de tutela entre o menino e o jaguar, novamente é possível perceber a isotopia alimentar. Ao levar o menino para casa para criá-lo, o jaguar vê a onça, sua esposa, logo querer comer o menino. Além disso, o próprio jaguar saia frequentemente para caçar, tendo trazido, em determinado momento, uma tatupeba como refeição.

O texto 2, embora mais econômico, também apresenta recorrências semânticas que se referem à isotopia alimentar. Para que o urubu apareça e Bahira possa lhe roubar o fogo, esse herói simula estar 
CLEBSON LUIZ DE BRITO - Sentido e realidade em mitos indígenas...

morto e com a carne já putrefata; em outras palavras, ele finge ser alimento de urubu. Além disso, quando a ave aparece, prepara o moquém, espécie de grelhas com varas, para poder usar o fogo e preparar a refeição em família, o que remete à isotopia alimentar.

Observando essa isotopia, percebemos que tudo nos textos diz respeito ao universo da alimentação. O fogo, nesse contexto, é tomado primordialmente como um artefato técnico-tecnológico que permite o preparo cultural dos alimentos, a cocção da carne. O projeto textual/discursivo das narrativas em questão, portanto, parece ser narrar, de forma simbólica e figurativa, o princípio da culinária, do trato cultural dos alimentos (sobretudo da carne), algo que eleva os homens em relação aos animais, distinguindo-os destes.

É na relação com o projeto textual/discursivo das narrativas que podemos compreender a seleção das figuras da onça, jaguar e urubu nos dois textos, bem como o porquê do traço semântico / humano/ que esses animais apresentam. Se notarmos bem, veremos que a escolha das figuras está ligada à isotopia alimentar de que falamos anteriormente. Onça, jaguar e urubu, na isotopia alimentar, guardam relação com o homem por remeterem, por assim dizer, a três diferentes regimes alimentares: o da carne crua (jaguar/onça), o da carne podre (urubu) e o da carne cozida (homem). Esses regimes podem ainda ser separados em duas esferas: uma da alimentação humana, isto é, a da carne cozida; e outra da alimentação animal, ou seja, a da carne crua, quer fresca, no caso da onça e do jaguar, quer podre, no caso do urubu6.

O fogo, por sua vez, se mostra o dispositivo técnico-tecnológico que permite que o processo natural da putrefação - que leva do fresco ao podre, respectivamente ligados às figuras do jaguar/onça e do urubu - seja suspenso em favor de um processo cultural: o cozimento. A figurativização observada nos textos, como se vê, não é aleatória, gratuita ou sem sentido, mas permite comparar regimes alimentares diferentes, colocando em relevo a prática alimentar humana, que é aquela mediada pela cultura.

\footnotetext{
${ }^{6}$ Lévi-Strauss (1991), já citado neste trabalho, observou, em várias narrativas ameríndias, essa oposição entre o cru e o cozido, oposição essa que dá nome ao primeiro volume das Mitológicas.
} 
Essa relação entre fogo e domínio cultural nos ajuda a entender ainda o fato de os atores onça/jaguar e urubus apresentarem um traço semântico /humano/, como dissemos. Esse traço pode ser percebido pela própria posse inicial do fogo pelos animais e a possibilidade de cozinhar a carne. Além disso, há outros elementos que indicam o estado inicialmente humanizado desses animais.

No texto 1, por exemplo, o jaguar acolhe o menino, limpa-o e alimenta-o, tal (ou quase tal) como uma mãe humana faz em relação a uma criança bem nova. Além disso, o jaguar tem esposa e casa, além de outros bens culturais como arco e flechas. Quanto ao texto 2, nele o urubu aparece ligado igualmente a bens e processos culturais que the conferem um traço semântico /humano/. Veja-se que, após o aviso da mosca varejeira, que indica o processo de putrefação (simulado por) de Bahira, o urubu prepara sua refeição em família, fazendo uso do moquém e do fogo para a cocção da carne. Além disso, os filhos do urubu brincam com flechinhas, como se fossem humanos, e o próprio narrador afirma que "o urubu era gente: tinha mãos".

O traço / humano/ dos animais detentores do fogo, como se pode ver, liga-se de forma coerente à condição destes antes das transformações de que os mitos analisados tratam. Na realidade (invertida) de então, os animais aparecem ligados ao domínio cultural, observado pela posse de diferentes artefatos e do fogo com o qual podiam preparar os alimentos. Nessa condição, ocupando o lugar que cabia ao homem, não é de se admirar que tais animais apresentassem o traço /humano/.

Esse traço ajuda, em outros termos, a configurar a realidade invertida que se via antes da conquista do fogo pelos homens/índios, quando o domínio cultural, algo exclusivamente humano, era privilégio dos animais. Com a conquista do fogo, os animais perdem esse domínio, que passa a ser exercido pelos homens/índios, ocorrendo nesse sentido o que podemos considerar um processo de desinversão ou normalização da realidade?.

\footnotetext{
${ }^{7}$ Com os termos desinversão e normalização pretendemos apreender de forma temática o processo subjacente à figurativização observada nas narrativas. Esse processo compreende um início invertido em relação a um fim marcado pela normalidade, o que pode, nesse sentido, ser associado à própria função do mito de narrar a passagem do caos à ordem.
} 
Vale ressaltar que essa operação narrativa de (re)criar uma realidade invertida em relação à realidade, por assim dizer, objetiva não ocorre apenas na narrativa mítica indígena. No mito judaico-cristão do surgimento do homem, por exemplo, é possível perceber o mesmo recurso. Esse mito, para explicar, entre outros elementos, uma realidade marcada pela morte do homem e pela necessidade de este assegurar sua sobrevivência à custa de sua própria força, apresenta uma realidade anterior invertida, em que um primeiro casal humano imortal vive de forma pura e ociosa em um paraíso. A perda dessa condição em função do pecado original é o que promove, nesse caso, a normalização ou desinversão da realidade, que passa a apresentar sua configuração "normal": em que o homem é mortal e deve assegurar sua sobrevivência à custa de sua própria força8 (os crentes dirão que se trata não de uma normalização, mas de uma deformação da condição primeira, que estes anseiam rever). O mito judaico-cristão e o das sociedades indígenas contempladas aqui, portanto, usam, para explicar diferentes dimensões da realidade, o mesmo modus operandi narrativo.

Dito isso, podemos, agora, examinar as narrativas selecionadas observando os elementos do nível fundamental, o que permite observar o que está na base do processo de normalização da realidade acima explicitado. A categoria semântica de base observada em ambos os textos é /natureza/ versus /cultura/, cujo termo eufórico é o segundo. O que figurativiza essa oposição no nível do discurso, como vimos, é a oposição entre, de um lado, práticas alimentares estritamente naturais e próprias dos animais e, de outro, a alimentação humana, esta mediada pela cultura.

Do ponto de vista das operações da sintaxe fundamental, podemos observar, inicialmente nos textos, uma negação ${ }^{9}$ do termo /natureza/, figurativizada discursivamente pela prática humana/indígena de secar a carne ao sol antes de comê-la, o que parece ser uma espécie de pré-culinária. Essa negação do termo /natureza/ pressupõe uma afirmação anterior desse mesmo termo. A

\footnotetext{
${ }^{8}$ Vide primeiros capítulos do livro de Gênese, o primeiro do Pentateuco.

${ }^{9}$ Ressaltamos que as operações de negação e afirmação aplicadas aos termos da oposição semântica de base não podem ser entendidas em absoluto com disposição mental ou atitude de personagens (atores discursivos). Trata-se, com efeito, de recursos teóricos abstratos e lógicos por meio dos quais, em semiótica, são analisadas as estruturas profundas dos discursos, o nível fundamental do percurso gerativo de sentido.
} 
CLEBSON LUIZ DE BRITO - Sentido e realidade em mitos indígenas...

conquista do fogo como dispositivo que permite o preparo cultural dos alimentos, por sua vez, figurativiza a afirmação da /cultura/.

Paralelamente a esse percurso fundamental envolvendo os homens/índios, ocorre um percurso inverso que responde pelo que se dá com os animais. Observá-lo nos permite explicitar a troca de lugares que ocorre entre homens/índios e animais, configurando o que denominamos desinversão ou normalização da realidade.

Os animais das narrativas, apesar de se ligarem inicialmente ao estado de /cultura/ pela posse, sobretudo, do fogo e apesar de apresentarem nesse momento o traço semântico /humano/, deixam entrever traços de sua natural animalidade. No texto 1, por exemplo, o jaguar, embora tenha o fogo e possa cozinhar a carne, em certo momento devora filhotes de arara crus que o menino joga para ele do alto do penhasco. A onça, esposa do jaguar, como vimos, tentava devorar o menino e mostrava-lhe as garras e os dentes, figuras que remetem à isotopia da animalidade. No texto 2, por sua vez, o urubu, igualmente detentor inicial do fogo, demonstra uma vocação para a dieta da carne podre, já que Bahira o atrai fingindo estar morto e com a carne putrefata.

Como se pode ver, enquanto no caso dos homens/índios observamos inicialmente uma operação de negação do termo /natureza/ figurativizada pela recusa em comer carne crua, secando-a ao sol, no caso dos animais percebemos uma tendência inversa. $O$ afloramento de traços da animalidade própria desses atores discursivos relaciona-se, no nível fundamental, à operação sintáxica de negação do termo /cultura/. A emergência de uma isotopia da animalidade nos detentores iniciais do fogo parece antecipar a iminente "naturalização" destes, o que ocorre após a perda do fogo para os homens/índios. Em outros termos, essa perda do fogo representa a realização de uma já prevista operação de afirmação do termo / natureza/ para os animais em questão, que deixam de estar ligados ao domínio da cultura e perdem a condição humana.

Constatamos, desse modo, dois percursos fundamentais paralelos que estão na base da narrativa de normalização da realidade observada nos dois textos. A conquista do fogo pelos homens/índios, como vimos, põe fim ao percurso /natureza/ $\rightarrow$ /não natureza/ $\rightarrow$ /cultura/, ao passo 
CLEBSON LUIZ DE BRITO - Sentido e realidade em mitos indígenas...

que a correlata perda do objeto pelos animais finda, no caminho inverso, o percurso /cultura/ $\rightarrow$ /não cultura/ $\rightarrow$ /natureza/.

\section{Conclusão}

Os mitos indígenas analisados acima apresentam, como pudemos observar, uma narrativa extremamente organizada, mobilizando, sob uma aparente simplicidade, um complexo jogo de sentidos. Em suma, ambos apresentam, como explicamos, uma narrativa marcada por um processo de normalização da realidade no que diz respeito ao domínio técnico-tecnológico que separa os homens dos animais, sobretudo quanto ao domínio da culinária.

Convém lembrar que a finalidade do mito como gênero do discurso é explicar (não no sentido científico do termo) a realidade, uma realidade marcada pela existência da lua no céu, das regras sociais, da morte, das práticas alimentares culturais e assim por diante. Para fazer isso e responder de forma simbólica às necessidades existenciais do homem, o mito (re)cria um passado fabuloso, um período primordial em que a realidade, antes invertida e/ou caótica, ganha sua feição normal (BRITO, 2011).

Os mitos que analisamos fazem isso. Para explicar uma realidade marcada pelo domínio cultural dos homens/índios e a sua ligação com a culinária (trato cultural dos alimentos), as narrativas examinadas (re)criam uma realidade anterior invertida em que o domínio cultural era privilégio de (determinados) animais. Tais textos, por isso, longe de apresentarem discursos caóticos, cumprem de forma coerente e organizada a sua função genérica.

Além disso, nos textos investigados, o fato de os animais apresentarem um traço semântico /humano/, como vimos, é coerente com a narrativa como um todo, na medida em que ajuda a configurar a realidade inicial invertida. Também não se trata de quaisquer animais. As figuras: onça, jaguar e urubu, como vimos, são usadas como investimentos discursivos para permitir uma comparação entre diferentes práticas alimentares ligadas à carne. Essa comparação, por sua vez, deixa evidente a diferença entre homem e animal; o primeiro 
aparece na realidade normalizada ligado a práticas alimentares mediadas pela cultura, algo possível aos animais apenas num remoto passado mítico invertido.

\section{Referências bibliográficas}

BARROS, Diana Luz Pessoa de. Teoria do discurso: fundamentos semióticos. São Paulo: Atual, 1988.

BERTRAND, Denis. Caminhos da semiótica literária. Bauru: EDUSC, 2003.

BRITO, Clebson Luiz de. Outras harmonias insuspeitas: um estudo da (in)variabilidade discursiva em mitos indígenas à luz da semiótica francesa. 2011. $116 \mathrm{f}$. Dissertação (Mestrado em Linguística do Texto e do Discurso) - Universidade Federal de Minas Gerais, [2011].

ELIADE, Mircea. Mito e realidade. São Paulo: Perspectiva, 2007.

FIORIN, José Luiz. Elementos de análise do discurso. São Paulo: Contexto, 2006.

GREIMAS, Algirdas Julien; COURTÉS, Joseph. Dicionário de semiótica. São Paulo: Contexto, 2008.

KRACKE, Waud. Parintintin. In: RICARDO, Fany P. (Org.). Enciclopédia dos Povos Indígenas no Brasil. São Paulo: Instituto Socioambiental, 2005. Disponível em: http://pib.socioambiental.org/pt/povo/parintintin . Acesso em: 17 set. 2009.

LARA, Glaucia Muniz Proença. O que dizem da língua os que ensinam a língua: uma análise semiótica do discurso do professor de português. Campo Grande: Ed. UFMS, 2004.

LARA, Glaucia Muniz Proença; MATTE, Ana Cristina Fricke. Ensaios de semiótica: aprendendo com o texto. Rio de Janeiro: Nova Fronteira/Lucerna, 2009.

LÉVI-STRAUSS, Claude. O cru e o cozido. São Paulo: Brasiliense, 1991.

MELATTI, Julio Cezar. Índios do Brasil. Brasília: Coordenada Ed. de Brasília, 1972.

MELATTI, Julio Cezar. Nota sobre a Música Craô. Disponível em: http://www.geocities.com/juliomelatti/artigos/a-muscra.htm . Acesso em: 30 ago. 2008.

SILVA, Alberto da Costa (Org.). Antologia de lendas do índio brasileiro. Rio de Janeiro: INL, 1957. 
CLEBSON LUIZ DE BRITO - Sentido e realidade em mitos indígenas...

TATIT, Luiz. A abordagem do texto. In: FIORIN, José Luiz (Org.). Introdução à Linguística I: objetos teóricos. São Paulo: Contexto, 2002. p. 187-209. 